\title{
Larger foraging range but similar habitat selection in non-breeding versus breeding sub-Antarctic penguins
}

\author{
JEAN-BAPTISTE THIEBOT ${ }^{1}$, AMÉLIE LESCROËL ${ }^{1}$, DAVID PINAUD ${ }^{1}$, PHILIP N. TRATHAN ${ }^{2}$ \\ and CHARLES-ANDRÉ BOST ${ }^{1}$ \\ ${ }^{1}$ Centre d'Etudes Biologiques de Chizé, UPR 1934 CNRS, 79360 Villiers-en-bois, France \\ ${ }^{2}$ British Antarctic Survey, NERC, High Cross, Madingley Road, Cambridge CB3 OET, UK \\ thiebot@cebc.cnrs.fr
}

\begin{abstract}
For land-breeding marine organisms such as seabirds, knowledge about their habitat use has mainly been gained through studies of breeding individuals that are constrained to return frequently to their breeding grounds. In this study we set out to measure whether: a) habitat selection in the non-breeding period predicts habitat selection in the breeding period, and b) whether breeding individuals concentrated their activity on the closest suitable habitats. Macaroni Eudyptes chrysolophus and gentoo Pygoscelis papua penguins, two marine predators with contrasting foraging strategies, were tracked from the Iles Kerguelen and their habitat selection investigated through Mahalanobis distances factorial analysis. This study presents the first data about gentoo penguins' juvenile dispersal. For both species, results showed 6.9 times larger maximum ranges and up to 12.2 times greater distances travelled during the non-breeding period. Habitat suitability maps suggested both species made similar environmental selections whatever the period. Macaroni penguins targeted pelagic areas beyond the shelf break while gentoo penguins always remained over the shelf. We consider the ecological significance of larger scale movements made outside the breeding period and suggest that this non-breeding period is of particular interest when attempting to understand an animal's habitat selection.
\end{abstract}

Received 4 June 2010, accepted 2 November 2010, first published online 5 January 2011

Key words: central place foragers, ecological niche, Iles Kerguelen, juvenile, winter

\section{Introduction}

Knowledge about the habitat selection made by marine vertebrates has increased considerably in recent years, especially in the Antarctic and sub-Antarctic ecosystems, mainly as a consequence of the growing use of telemetry techniques (e.g. McConnell et al. 2002, Weimerskirch et al. 2007). Among marine vertebrates, seabirds have received a greater level of attention, possibly because they are ground nesting and usually easy to manipulate and to recapture (e.g. Wilson et al. 2002). However, most seabird tracking data have been gathered during the breeding period, when animals are tightly linked to their breeding site in order to provision their offspring (e.g. Trathan et al. 2006, Weimerskirch 2007). Consequently, our knowledge about their habitat usage outside the breeding period is very limited. Moreover, since these animals spend a substantial part of their life not linked to a central place, including during juvenile periods and during interbreeding life-cycle phases, filling this gap is a priority for investigation (e.g. Grémillet et al. 2000, Phillips et al. 2005, 2006, Bost et al. 2009). Outside the breeding period, seabirds are very much less constrained in space and time, and no longer behave as central place foraging animals (Croxall et al. 2005, Bost et al. 2009). Free from breeding constraints, such animals may therefore reach other areas. However, differences in habitat selection during the different periods remain poorly documented (Grémillet et al. 2000, Phillips et al. 2006).

In this study we investigated the habitat selections made by two marine predators breeding on the Iles Kerguelen, in the southern Indian Ocean. This archipelago is surrounded by a large peri-insular submarine plateau that offers a range of habitats (from shallow productive areas over the plateau, to the steep shelf slopes and outer abyssal plains) to the abundant and diverse community of seabirds that breed on the islands (Weimerskirch et al. 1988). Among this community, penguins (Spheniscidae) are a key group. These diving seabirds represent c. $90 \%$ of the Southern Ocean's bird biomass and consume several million tons of marine resources annually (Williams 1995). The foraging range of penguins is constrained by their relatively slow travelling mode (submerged swimming and porpoising), which strongly limits their dispersal from the colony, in comparison with flying seabirds. Moreover, this group includes species that have contrasted foraging strategies, for example the macaroni Eudyptes chrysolophus Brandt and the gentoo Pygoscelis papua Forster penguins (Mori \& Boyd 2004), two species that breed at Kerguelen. 
Our main objectives were to determine whether habitat use in the interbreeding period predicted habitat use during the breeding period, and whether the constraints imposed by breeding lead individuals to forage in the nearest suitable habitat. To accomplish this, we assessed habitat selection of macaroni and gentoo penguins in both periods. These are ideal species to compare, since they have contrasting life history patterns: the macaroni is a pelagic predator (diving typically to $40 \mathrm{~m}$ ) while the gentoo generally forages closer to shore and has deeper diving capabilities (Mori \& Boyd 2004, Tanton et al. 2004, Bost et al. 2009). We hypothesized that the habitat selected outside the breeding period would better inform our understanding of each species preferred foraging habitat than during the breeding period, due to the release of constraints associated with offspring and greater time availability. We made the prediction that habitat selection by breeding penguins is highly correlated with habitat selection by penguins during the interbreeding period, but over a much smaller area.

In order to test these predictions, we compared the movements of remotely tracked animals during and outside the breeding periods (Grémillet et al. 2000, Phillips et al. 2006). We modelled the habitat selected outside the breeding period, then applied this model to the area that was theoretically within the range of breeding birds. Finally, we compared the model predictions with the actual tracks of the breeding individuals to infer whether the latter behave similarly to non-breeding animals with a smaller foraging range.

\section{Materials and methods}

\section{Study models}

Macaroni penguins have the greatest prey biomass consumption of any seabird species in the world (Brooke 2004) and they are also the most numerous penguin species with 11.8 million breeding pairs worldwide (Woehler 1993). Macaroni penguins are a specialist predator, targeting small, swarming pelagic prey (mainly crustaceans), but also myctophid fish, especially in the Kerguelen region (Deagle et al. 2008). Gentoo penguins are one of the most widespread penguin species in the southern oceans and are one of the main avian benthic consumers of the subAntarctic (e.g. Croxall \& Prince 1980). Interestingly, gentoo penguins' ecology from neighbouring localities on Kerguelen may reflect the whole range of variation of the species with respect to foraging behaviour and diet (Lescroël et al. 2004, Lescroël \& Bost 2005).

\section{Remote tracking of the animals}

For macaroni penguins, our investigation of habitat use outside the breeding period was based on the interbreeding migration of 12 animals tracked using light-based geolocation methods (GLS) in 2006 (see Bost et al. 2009

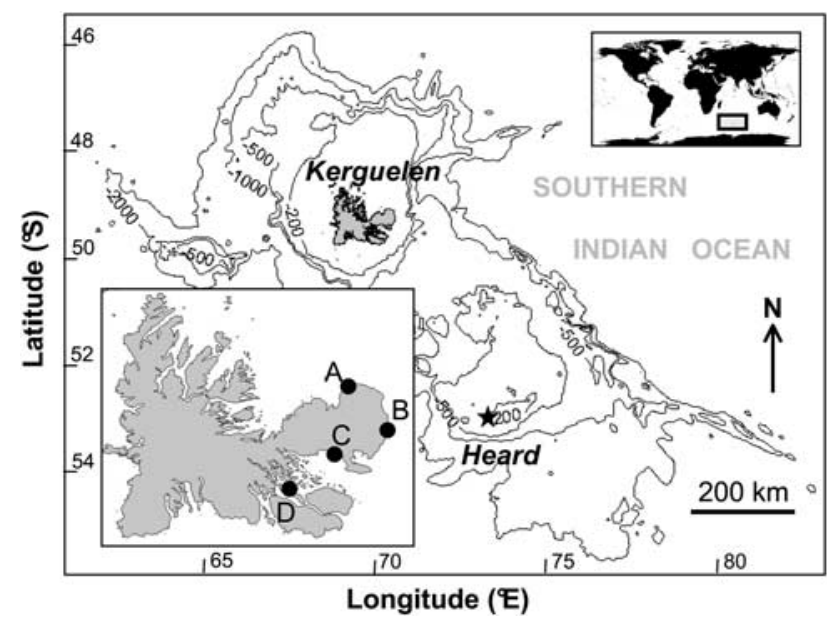

Fig. 1. Map showing the location of Iles Kerguelen and Heard Island on the Kerguelen Plateau. Isobaths for 200, 500, 1000 and $2000 \mathrm{~m}$ are shown. The colonies from where animals were instrumented are indicated by letters $(\mathrm{A}=$ Cape Cotter, $\mathrm{B}=$ Estacade, $\mathrm{C}=$ Pointe Denis, $\mathrm{D}=$ Longue Island).

for further details on the loggers used and attachment methods). Spatial accuracy of locations obtained with GLS technique is expected to be from tens to hundreds of kilometres (Wilson et al. 2002). Data on the breeding period were obtained between December 2000 and January 2001 during the chick-brooding stage, when males need to replenish their energetic reserves at sea after a prolonged fasting period ashore of about 39 days (Stahl et al. 1985). Three breeding males were instrumented with ARGOS Platform Terminal Transmitters (PTTs, Kiwisats 101, 45 sec transmission rate). The PTTs were fitted medially to the lower back to reduce drag, and fixed to the back feathers using cyanoacrylate glue (Loctite 401) and secured cable ties. Devices represented $1.9 \%$ of body mass and $2.7 \%$ of the bird's cross-sectional area (Williams 1995). PTTs provide locations with an accuracy that can be better than one kilometre (for the classes of location coded 3, $2 \& 1$, see review in Wilson et al. 2002). Both PTTs and GLSs were deployed at the same colony: Cape Cotter, on the Kerguelen mainland (Fig. 1).

Habitat use by gentoo penguins outside their breeding period was investigated using dispersing juveniles. Though these birds may have been less experienced at foraging than adults, we consider that their habitat selection was probably representative of other demographic categories, as our study birds clearly had to make choices between available habitats during the periods they carried the devices. We equipped six birds with ARGOS PTTs (Kiwisats 202, 45 sec transmission rate) between January and March 2008 on the Kerguelen mainland; three individuals were tracked from the Estacade colony, a site facing eastwards to the open sea, and three from Pointe Denis, within the Golfe du Morbihan. These devices were programmed to transmit for 
24 hours every other day. A haulout timer was set to activate after 12 hours continuously dry. They were attached in the same manner as for breeding macaroni penguins, and represented $1.7 \%$ of body mass and $3.8 \%$ of the bird's cross-sectional area. Habitat use by gentoo penguins during the breeding period was investigated through 11 adults tracked with PTTs between September and October 2002 (eight individuals from Estacade colony and three from Longue Island, in the Golfe du Morbihan). These animals were incubating eggs $(n=8$, with five of them from Estacade and three from the Golfe du Morbihan) or brooding young chicks $(n=3$, all from Estacade). These results have been published previously (see Lescroël \& Bost 2005, who also provide details about the loggers used and the attachment methods).

For both species, data collection during breeding and non-breeding periods could not take place during the same year due to logistic constraints. As tracking datasets potentially reflect unique ecological conditions within a given year at a given locality, we ensured that the nonbreeding periods were not investigated during times of marked local thermal anomalies (sea surface temperature anomalies data from the NASA's POET-PO.DAAC website http://poet.jpl.nasa.gov/, accessed September 2010). For the breeding periods investigated, we felt confident that thermal anomaly was a small concern, since previous studies showed consistent at-sea trips patterns among seven consecutive years for breeding macaroni penguins (Trathan et al. 2006).

\section{Habitat selection analysis}

We considered that a suitable habitat comprised a combination of environmental factors that was favourable to the study animals (Guisan \& Zimmermann 2000). Here, we used environmental variables that were: a) available for all tracking data (year, season, locality, scale), and b) thought to have a large and contrasting influence on foraging behaviour for each species. Given previous information about the respective foraging strategies of the two species (Mori \& Boyd 2004, Lescroël \& Bost 2005, Deagle et al. 2008), we focused on bathymetry, bathymetry gradient and distance to the colony. The use of the distance to the colony allowed us to measure the difference of spatial scale of the movement according to the level of time constraint (from days, during the breeding period, to months or maybe years outside the breeding period). The spatial grids used for the model inputs and outputs were $0.1^{\circ}(c .10 \mathrm{~km})$ for macaroni penguins, and $0.033^{\circ}(c .3 \mathrm{~km})$ for gentoo penguins, to take into account that different devices were used to track the individuals outside the breeding period. The spatial resolution of the model predictions for the breeding period, were therefore dependent on the accuracy of the model's inputs.

Before analysing animal movements, ARGOS locations were filtered using the 'sdafilter' function of R package 'argosfilter' based on speed and spikes along the observed track. Specific speed thresholds used were $7.5 \mathrm{~km} \mathrm{~h}^{-1}$ for macaroni (Brown 1987) and $7.2 \mathrm{~km} \mathrm{~h}^{-1}$ for gentoo (Robinson \& Hindell 1996) penguins. Filtering locations ensured that their accuracy adequately fitted into the spatial scale used for the model. Because we were unable to know the precise location of selected foraging places, or the success of the animals in these places, we used all the filtered locations in the habitat selection analysis, including the travelling parts of the trips. Due to the irregular nature of ARGOS locations, we also used a linear interpolation of the track (once every hour) to avoid over-sampling in the models for areas where many locations were produced. Light-based geolocation data were approximately constant, with one location produced each 12 hours (see Wilson et al. 2002 for a review).

Finally, we used a habitat suitability model to understand habitat selection outside the breeding period. Modelled habitat selection criteria were then applied within the theoretical foraging ambit of animals during the breeding period. Thus, we predicted favourable areas for breeding animals, based on knowledge gained from non-breeding animals and under the assumption that their preferred habitat was constant within (macaroni penguins and gentoo penguins) and between (gentoo penguins inside the Golfe du Morbihan) colonies. We used Mahalanobis distances factor analysis (MADIFA, Calenge et al. 2008), a method developed to build habitat suitability maps from presence-only data, such as tracking data. The Mahalanobis distance is a commonly used environmental suitability index (see Calenge et al. 2008 and references therein) that expresses the distance between each available point on a map (defined by a set of environmental variables) and the mean of the ecological niche (supposed to reflect the environmental optimum for the studied species). For all points on the map, the MADIFA partitions the ecological space into a set of axes by the means of two successive principal components analyses (PCAs), so that the first axis maximises the average proportion of their squared Mahalanobis distances. The first PCA returns the directions partitioning the variance of standardized niche into orthogonal components. Then, the correlation structure is removed by rescaling the variance of all axes to one, and a second PCA performed on this new matrix returns linear combinations of the environmental variables so that the width of the niche is the smallest in comparison to the width of the cloud of available points (Calenge et al. 2008). Among the different methods available for the description of the ecological niche, we chose the MADIFA because it takes into account the environmental availability on the area where the niche was sampled, and consequently may provide better predictive accuracy (for a comparison of the results given by six presence-only data methods see Tsoar et al. 2007). This method is also convenient to use because it is easily available and implemented, runs on a free software, and finally because it is complementary to the commonly used ecological-niche factor analysis (ENFA). For all analyses we used R 2.9.0 


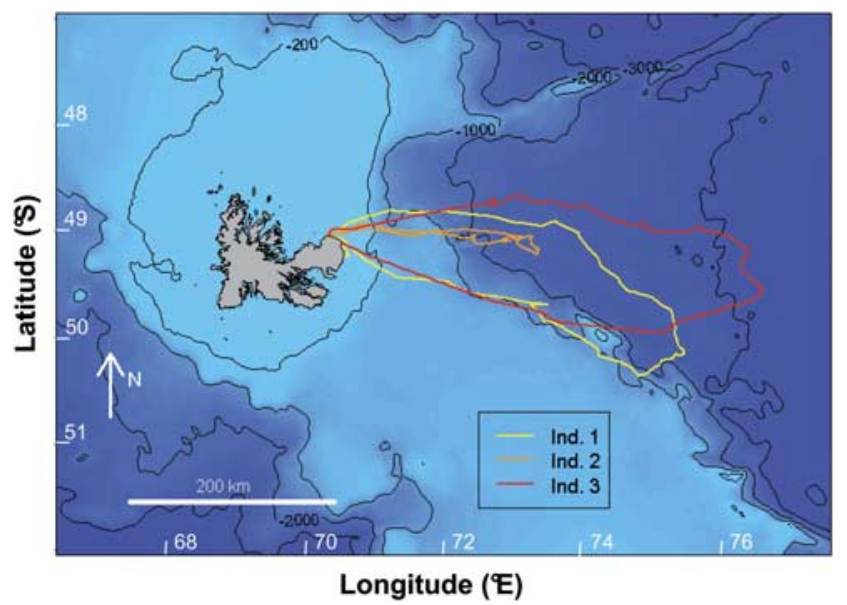

Fig. 2. Satellite tracking of three adult male macaroni penguins from the Cape Cotter colony during the chick-brooding stage. Isobaths for 200, 1000, 2000 and $3000 \mathrm{~m}$ are shown.

(R Development Core Team 2009) and additional packages 'adehabitat', 'sp', and 'trip'.

To perform the MADIFA we needed to define spatially the 'available environment' considered for non-breeding animals. We selected the latitudinal range they travelled in, but extended the longitudinal boundaries of their observed dispersion to their maximal range plotted in both directions. During the breeding period, we defined the maximal theoretical foraging range for birds using time budget information (Williams 1995), speed (Brown 1987, Robinson \& Hindell 1996) and the proportion of time spent travelling (38\%, Brown 1987). As there were apparent differences in habitat targeted by gentoo penguins from the different localities (open ocean compared to Golfe du Morbihan, see also Lescroël \& Bost 2005), habitat suitability was modelled separately between localities.

\section{Results}

\section{Movements of animals}

On average, macaroni penguins left their colony for their interbreeding migration on 19 April \pm 14 days, and returned six months later, on 24 October \pm 6 days. All birds migrated in a similar direction, moving eastwards away from their colony over the open ocean beyond the shelf. They remained in this habitat during the whole interbreeding period. During the brood period, trips made by males lasted 16 days on average: individuals left their nests on approximately 2 January and returned around 17 January. Movements were generally eastwards and all birds reached oceanic areas beyond the Kerguelen Plateau, over depths of $2000 \mathrm{~m}$ (Fig. 2). Table I shows that the much longer duration of the interbreeding trips compared to the brooding trips $(188.8 \pm 14.8$ vs $16.6 \pm 3.8$ days, respectively, Wilcoxon rank sum test, $\mathrm{W}=0, P<0.01$ ) was associated with a much
Table I. Tracking duration, minimum distance travelled and maximum range reached from the colony for individual winter (W) (from supplementary material of Bost et al. 2009) and brooding (B) trips.

\begin{tabular}{lccc}
\hline $\begin{array}{l}\text { Macaroni } \\
\text { penguin trip }\end{array}$ & $\begin{array}{c}\text { Tracking } \\
\text { duration } \\
\text { (days) }\end{array}$ & $\begin{array}{c}\text { Min. distance } \\
\text { travelled } \\
(\mathrm{km})\end{array}$ & $\begin{array}{c}\text { Max. range } \\
\text { reached } \\
(\mathrm{km})\end{array}$ \\
\hline W-1039 & 160 & 10518 & 2868 \\
W-1065 & 169 & 10885 & 2013 \\
W-1067 & 181 & 13434 & 3680 \\
W-1339 & 201 & 10834 & 3143 \\
W-1340 & 192 & 9481 & 2158 \\
W-1343 & 200 & 9681 & 1846 \\
W-1344 & 194 & 9504 & 1460 \\
W-1345 & 204 & 11907 & 3561 \\
W-1347 & 191 & 10563 & 3443 \\
W-1349 & 201 & 10263 & 3030 \\
W-1350 & 187 & 8739 & 812 \\
W-1351 & 197 & 9354 & 977 \\
B-1 & 20 & 966 & 390 \\
B-2 & 13 & 536 & 222 \\
B-3 & 17 & 1063 & 454 \\
\hline
\end{tabular}

greater maximum range $(2416 \pm 1008$ vs $356 \pm 120 \mathrm{~km}$, Welch two sample $t$-test, $t=-6.888, \mathrm{df}=12.065, P<0.01)$ and greater minimum distance travelled $(10431 \pm 1278$ vs $855 \pm 281 \mathrm{~km}, \mathrm{~W}=0, P<0.01$ ), without any overlap in the two groups compared in each case.

For gentoo penguins, juveniles first seemed to remain in the waters immediately adjacent to the colonies, since no movement could be inferred from the locations received and the transmitters never entered the 'haulout' mode. This first phase was therefore excluded from the analyses. In a second phase, starting between 29 January and 31 March

Table II. Tracking duration, minimum distance travelled and maximum range reached from the colony for individual gentoo penguins, adult (A) (from Lescroël \& Bost 2005) and juvenile (J). Bird originated from colonies facing open sea $(\mathrm{O})$ or inside the Golfe du Morbihan (I).

\begin{tabular}{lccc}
\hline & $\begin{array}{c}\text { Tracking } \\
\text { duration } \\
\text { (hours) }\end{array}$ & $\begin{array}{c}\text { Min. distance } \\
\text { travelled } \\
(\mathrm{km})\end{array}$ & $\begin{array}{c}\text { Max. range } \\
\text { reached } \\
(\mathrm{km})\end{array}$ \\
\hline JO-1 & 324 & 355 & 165 \\
JO-2 & 577 & 773 & 493 \\
JO-3 & 48 & 10.5 & 5.4 \\
JI-1 & 768 & 727 & 119 \\
JI-2 & 5089 & 448 & 91 \\
JI-3 & 863 & 763 & 165 \\
AO-2* & 56 & 58 & 23 \\
AO-3 & 130 & 197 & 44 \\
AO-9 & 43 & 53 & 18 \\
AO-10 & 92 & 93 & 46 \\
AO-17* & 127 & 138 & 38 \\
AO-18 & 92 & 79 & 34 \\
AO-19* & 82 & 39 & 19 \\
AO-20 & 104 & 76 & 31 \\
AI-7 & 79 & 38 & 9 \\
AI-8 & 165 & 107 & 11 \\
AI-9 & 56 & 14 & 3 \\
\hline
\end{tabular}

*adults brooding chicks (other adults were incubating). 


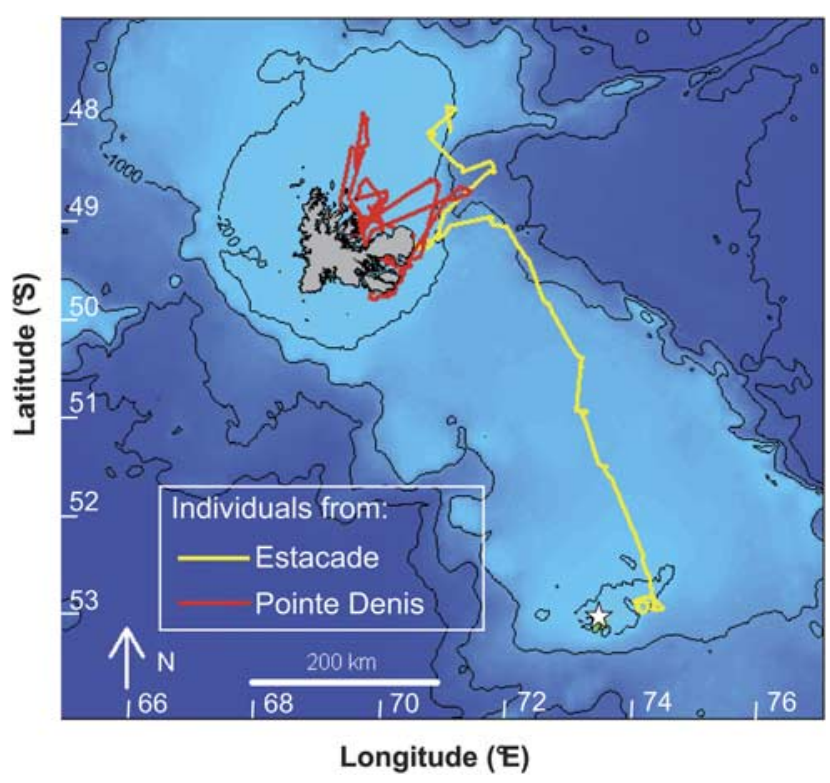

Fig. 3. Satellite tracking of six juvenile gentoo penguins from Estacade (3 individuals, yellow tracks) and Pointe Denis (3 individuals, red tracks) during dispersal. Isobaths for 200, 1000,2000 and $3000 \mathrm{~m}$ are shown. The star shows the location of Heard Island.

(7-33 days after deployment), juveniles dispersed further away from their colony. All transmitters generally operated for hundreds of hours during this juvenile dispersion (Table II). Surprisingly, for four of the six birds, transmissions all ended on 2 April. Juveniles from the open sea locality showed a linear dispersal pattern and appeared to target the shelf break with depths between 200 and $500 \mathrm{~m}$ (Fig. 3). In the first 20 days one of these juveniles (coded JO-2 in Table II) reached the vicinity of Heard Island, situated c. $430 \mathrm{~km}$ to the south-east of Kerguelen, where it remained until transmissions stopped. All juveniles from the Golfe du Morbihan reached the open sea (after 8-25 days) and thereafter stayed close to the north-east and south-east coastlines, using bays and fjords shallower than $200 \mathrm{~m}$ (Fig. 3). For one of them (coded JI-2 in Table II), transmissions were lost on 2 April but started again nearly six months later, in September, for several days. For this bird we deleted the interpolated points during this gap in order to not overweight this area in our model, even if locations on each side of the gap were only $54.6 \mathrm{~km}$ apart.

On average, breeding gentoo penguins performed trips of 2.21 days duration in the open ocean locality and 3.65 days inside the Golfe du Morbihan. Animals from the open ocean locality radiated in an eastern direction from the colony, mainly over the 100-200 m isobaths, with one bird reaching the $500 \mathrm{~m}$ isobath. Adults from the Golfe du Morbihan showed shorter maximum ranges, and stayed inside the gulf, foraging between the islands neighbouring their colony. Tracking for the juvenile dispersal lasted
Table III. Summary of the MADIFA for macaroni penguins during the interbreeding period. Percentage of variance explained by each principal component of the PCAs and scores of the variables on those components.

\begin{tabular}{lcccccc}
\hline & \multicolumn{3}{c}{ First } & \multicolumn{3}{c}{ Second } \\
& PCA components & \multicolumn{2}{c}{ PCA components } \\
& 1 & 2 & 3 & 1 & \multicolumn{1}{c}{2} & 3 \\
\hline \% of variance & 44.9 & 32.6 & 22.4 & 55.6 & 41.3 & 3.2 \\
Bathymetry & 0.69 & -0.07 & 0.72 & 0.74 & 0.63 & 0.04 \\
Gradient of bathymetry & -0.31 & -0.93 & 0.21 & -0.09 & -0.09 & -0.99 \\
Distance to colony & -0.65 & 0.37 & 0.66 & -0.87 & 0.54 & -0.04 \\
\hline
\end{tabular}

much longer than the trips of breeding adults (Table II; $1278 \pm 1890$ vs $93.4 \pm 36.6$ hours, respectively, $\mathrm{W}=10$, $P=0.02$ ). This was associated with greater maximum range $(173.0 \pm 167.7$ vs $25.1 \pm 14.4 \mathrm{~km}, \mathrm{~W}=10, P=0.02)$ and greater minimum distances travelled $(512.8 \pm 302.5$ vs $81.0 \pm 52.0 \mathrm{~km}, \mathrm{~W}=11, P<0.03)$.

\section{Habitat selection of macaroni penguins}

The MADIFA model for the interbreeding period of macaroni penguins, using two principal components, explained more than $96.8 \%$ of the total variance observed between the tracks and the environment (Table III, second PCA). The corresponding map of habitat suitability for macaroni penguins during interbreeding period showed two main suitable areas (Fig. 4a), matching waters mainly 3000-3500 m deep, while depths shallower than $1500 \mathrm{~m}$ and deeper than $5000 \mathrm{~m}$ appeared as very unfavourable. The larger of the two suitable areas lies east of Kerguelen, corresponding to locations used by the tracked animals. The smaller one was found to the west of Kerguelen in the region between $30^{\circ} \mathrm{E}$ and $50^{\circ} \mathrm{E}$, and was separated from the other by an unfavourable area in the vicinity of the western
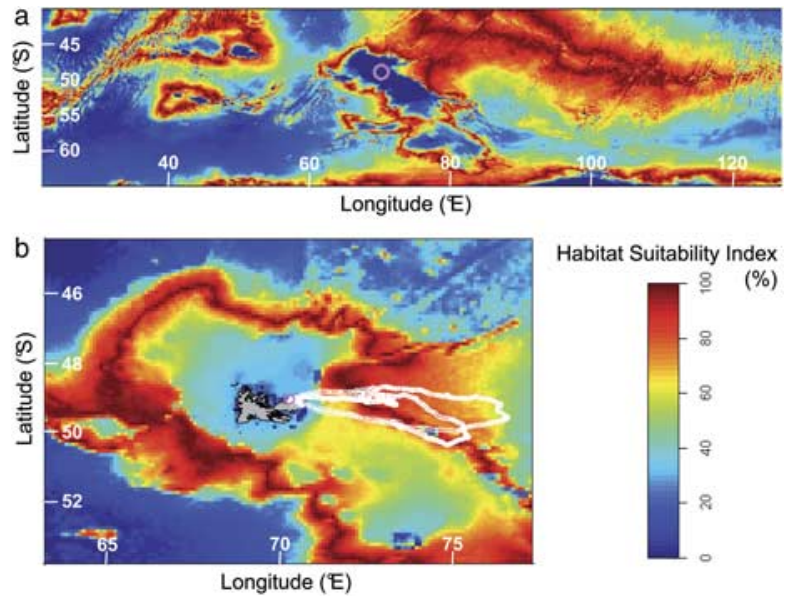

Fig. 4. Habitat suitability map for macaroni penguins during: a. the interbreeding period, and b. the chick-brooding period, with superimposed tracks (white circles) of individuals at the corresponding stage of the year. The bold circle indicates the location of the colony. 
Table IV. Summary of the MADIFA for dispersing juvenile gentoo penguins from the open sea locality. Percentage of variance explained by each principal component of the PCAs and scores of the variables on those components.

\begin{tabular}{|c|c|c|c|c|c|c|}
\hline & \multicolumn{3}{|c|}{$\begin{array}{c}\text { First } \\
\text { PCA components }\end{array}$} & \multicolumn{3}{|c|}{$\begin{array}{c}\text { Second } \\
\text { PCA components }\end{array}$} \\
\hline & 1 & 2 & 3 & 1 & 2 & 3 \\
\hline$\%$ of variance & 52.7 & 33.2 & 14.1 & 96.1 & 3.7 & 0.1 \\
\hline Bathymetry & 0.71 & -0.03 & -0.71 & 0.98 & -0.22 & -0.30 \\
\hline Gradient of bathymetry & -0.08 & -0.99 & -0.05 & -0.04 & 0.06 & -0.94 \\
\hline Distance to colony & -0.70 & 0.09 & -0.70 & -0.72 & -0.67 & 0.21 \\
\hline
\end{tabular}

Kerguelen Plateau. Very low habitat suitability levels were also found over the entire Kerguelen Plateau.

For breeding macaroni penguins, the maximum theoretical range from the colony was estimated to be $513 \mathrm{~km}$ for a 15 day chick-brooding trip. In the area delimited within this radius, the habitat selection model enabled us to build a map of habitat suitability for breeding macaroni penguins (Fig. 4b). Here again, the area encompassing the Kerguelen Plateau showed low levels of suitability, with much higher levels of suitability found at the edges of the shelf. Tracks from the breeding animals superimposed on the modelled habitat showed that birds swam to the closest suitable area to their colony (Fig. $4 \mathrm{~b}$ ).

\section{Habitat selection of gentoo penguins from the open sea locality}

The MADIFA model for juvenile gentoo penguins from Estacade colony was dominated by bathymetry (Table IV,
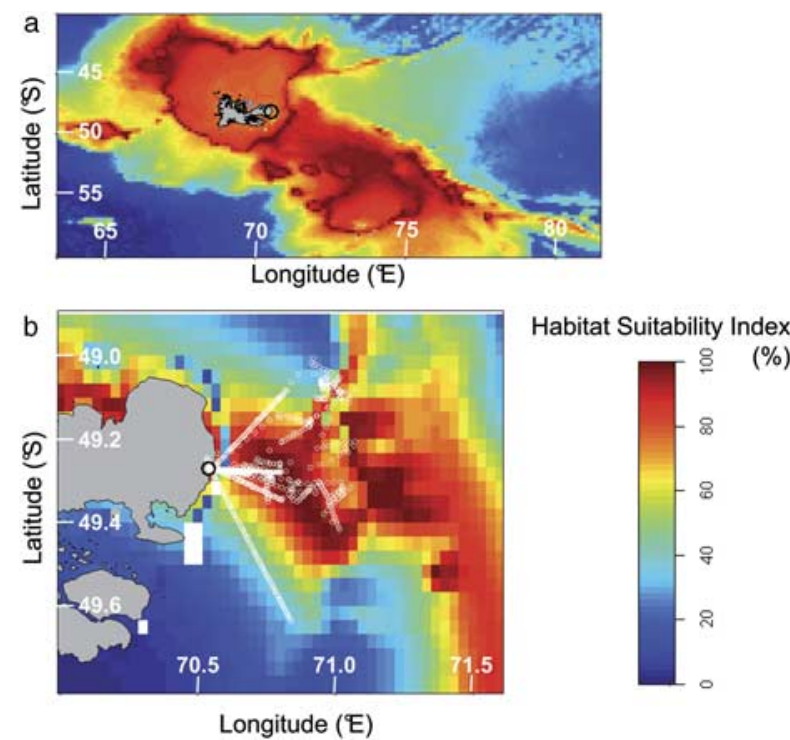

Fig. 5. Habitat suitability map for gentoo penguins from Estacade colony during: a. the juvenile dispersal, and b. the breeding period, with superimposed tracks (white circles) of individuals at the corresponding stage of the year. The bold circle indicates the location of the colony.
Table V. Summary of the MADIFA for dispersing juvenile gentoo penguins from the Golfe du Morbihan. Percentage of variance explained by each principal component of the PCAs and scores of the variables on those components.

\begin{tabular}{lrrrrrr}
\hline & \multicolumn{3}{c}{ First } & \multicolumn{3}{c}{ Second } \\
& \multicolumn{2}{c}{ PCA components } & \multicolumn{2}{c}{ PCA components } \\
& 1 & 2 & \multicolumn{1}{c}{3} & \multicolumn{1}{c}{1} & \multicolumn{1}{c}{2} & \multicolumn{1}{c}{3} \\
\hline \% of variance & 51.9 & 33.2 & 14.8 & 89.3 & 10.7 & 0.02 \\
Bathymetry & 0.71 & -0.03 & 0.71 & 0.99 & 0.46 & -0.26 \\
Gradient of bathymetry & -0.09 & -0.99 & 0.05 & -0.05 & -0.04 & 0.96 \\
Distance to colony & -0.70 & 0.10 & 0.70 & -0.68 & 0.49 & 0.28 \\
\hline
\end{tabular}

second PCA: $96.0 \%$ of the variance explained on the first principal component). Suitable areas were restricted to the Kerguelen Plateau, where depths were shallower than $1000 \mathrm{~m}$ (Fig. 5a). The highest suitability levels over the plateau corresponded to specific isobaths around $500 \mathrm{~m}$.

The maximum theoretical range from the colony calculated for breeding gentoo penguins (regardless of the colony location) was estimated to be $98.5 \mathrm{~km}$ for a three day trip. In the area delimited within this radius, the modelled environment developed from the MADIFA enabled us to build a map of habitat suitability for the breeding gentoo penguins (Fig. 5b). This map predicted a single strip of suitable habitat, oriented NW-SE, which passed near to the breeding colony. On each side of this strip there were areas of very low habitat suitability. Tracks from breeding adults superimposed on the modelled habitat showed they mostly utilized the area highlighted, with the highest ARGOS location densities over the areas of highest suitability. However, two very linear tracks occurred over areas predicted as much less suitable.
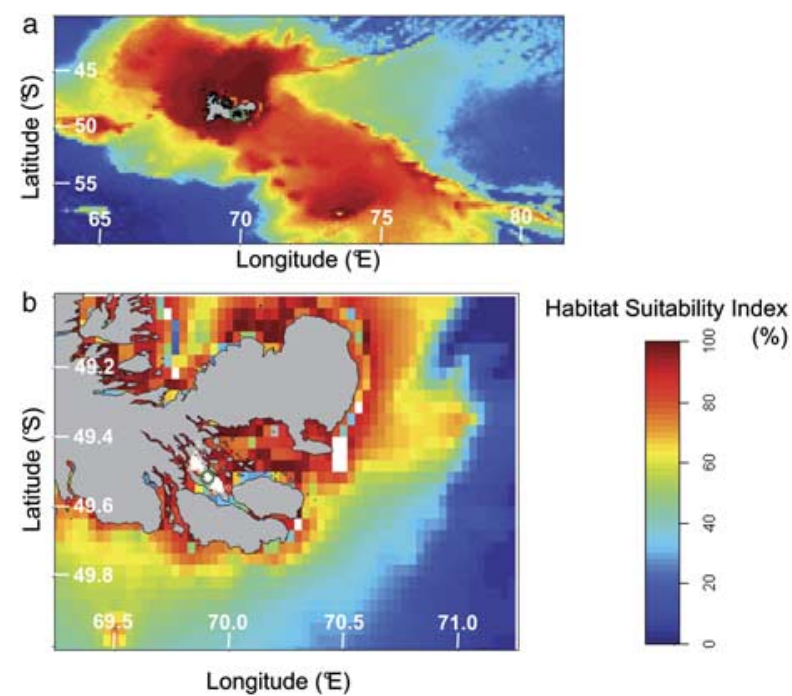

Fig. 6. Habitat suitability map for gentoo penguins from the Golfe du Morbihan during: a. the juvenile dispersal, and b. the breeding period, with superimposed tracks (white circles) of individuals at the corresponding stage of the year. The bold circle indicates the location of the colony. 
Habitat selection of gentoo penguins from the Golfe du Morbihan

The MADIFA model for the Golfe du Morbihan showed only slight differences from the analyses carried out for juveniles from the open sea colony (Table V). The map of habitat suitability for these dispersing juvenile gentoo penguins (Fig. 6a) confirmed that the Kerguelen Plateau was the only suitable area available to them. However, in the case of the birds from the Golfe du Morbihan the areas with the highest habitat suitability were found in shallower areas $(<200 \mathrm{~m}$ deep), closer to the coasts of Kerguelen and Heard Island than was obtained for birds from the open sea locality.

For the breeding gentoo penguins from the Golfe du Morbihan, the map of habitat suitability predicted from the MADIFA showed that the most favourable areas were fragmented and occurred across the Kerguelen Plateau, with the highest levels of habitat suitability found inside the gulf and along the north coastline of Kerguelen (Fig. 6b). Tracks of breeding adults corresponded closely with the most favourable areas found inside the gulf.

\section{Discussion}

This study measured the effects of breeding constraints on the foraging range and habitat selection of two contrasting penguin species, using both previously published data and new datasets describing animal movements, to develop habitat suitability maps. This study also provides the first data on the juvenile dispersal of gentoo penguins.

Our first prediction (i.e. that the release of constraints associated with breeding will lead to a larger foraging range and greater distances travelled) was strongly supported by the results obtained from both models. Macaroni penguins showed an elevenfold increase in their at-sea time between chick-brooding and interbreeding trips, this was associated with significantly greater maximum range (6.8 times more) and minimum distance travelled (12.2 times more). For gentoo penguins, the same pattern was also observed although the juvenile dispersal was not exhaustively covered by the telemetric survey. Maximum range was at least 6.9 times more than for breeding individuals, while the distance travelled was at least 6.3 times more. Gentoo penguins are generally thought to be sedentary outside the breeding period, foraging at sea during the day but returning to the colony or a similar terrestrial habitat during the night, with similar at-sea movements in the post-breeding period to those during the breeding season (Bost \& Jouventin 1990, Wilson et al. 1998, Tanton et al. 2004). However, our data, the first describing the juvenile dispersal for this species, shows that juveniles migrate over a much larger scale than previously thought and over a larger scale than breeding adults.

Our second prediction (i.e. that breeding animals only exploit the closest suitable habitats) was also largely supported by both study models. The tracks of breeding individuals appeared to closely match with the nearest suitable habitats predicted by the larger scale behaviour of non-breeding birds. On Kerguelen, the two penguin species appear to segregate in space, with a spectacular contrasting use of the Kerguelen Plateau. Macaroni penguins exploited areas beyond the shelf break in both breeding and interbreeding periods, while gentoo penguins seemed to be always restricted to the shelf area. This segregation in space reflects the different exploitation of the environment (diving mode and diet) between the gentoo, a plastic, inshore forager, and the pelagic specialist macaroni penguin (Lescroël \& Bost 2005, Deagle et al. 2008).

The greatest discrepancy for our model was for breeding gentoo penguins from the open ocean colony, which did not always closely match with the predicted areas of habitat suitability (Fig. 6b). However, these tracks only consisted of a very few ARGOS locations (Lescroël \& Bost 2005) and the patterns observed were produced by the linear re-interpolation of the tracks. Conversely, aggregations of ARGOS locations matched the areas of maximum suitability levels. Interestingly, these areas also matched the known distribution of benthic nototheniid fish targeted by gentoo penguins (Lescroël et al. 2004). For gentoo penguins from the Golfe du Morbihan, suitable habitats predicted for breeding adults also corresponded to areas of high zooplankton production during the summer (Lescroël et al. 2004).

\section{Why larger scale movements for non-breeding individuals?}

Outside the breeding period, it has been shown that macaroni penguins remain consistently at sea (Bost et al. 2009). In contrast gentoo penguins do return ashore during the winter (see above). Our results lead us to question why in both species, animals that are free from breeding constraints move over a larger scale, even when suitable habitat areas seem available within a smaller radius. We suggest that two important facts are crucial. Firstly, the habitat suitability index given by the MADIFA is only relative. Hence, the suitability of a specific area depends not only on the suitability calculated for the area itself, but also on the entire region considered to be available in the wider environment. More favourable habitats may therefore be found outside the spatial range displayed for breeding adults (compare Fig. $4 \mathrm{a} \& \mathrm{~b}$ ). Second, our results suggest habitat selection is constant, which implies that animals may actually track a specific set of environmental conditions. Prey availability is a key among these latter, and probably is not constant but rather varies according to the life cycle of the prey itself and to predator activity around the colony (Ashmole 1963, Birt et al. 1987, Charrassin et al. 2002, Ainley et al. 2004). According to the season, the suitable environmental conditions targeted 
by the predator may therefore occur distantly from the colony. Such factors drive the breeding phenology of a species (Durant et al. 2005), and it is therefore probable that species have evolved so as to match their breeding season to a time period that allows them to most easily find predictable prey in the vicinity of their colony. Further, larger scale movements outside the breeding period minimize any potential intra-specific competition for food at a time when food availability may be lower (Clarke 1988, Koslov et al. 1991).

\section{Limits of this study}

Although a reasonable number of individuals were equipped during both the interbreeding period of macaroni penguins and the breeding period of gentoo penguins from the open sea, only a limited number of devices were available for breeding macaroni and juvenile gentoo penguins. These low numbers might be an issue where we wish to have an exhaustive or at least an unbiased sampling relevant to capturing the patterns of the penguins' ecological niche (see Calenge et al. 2008). However, a similar directional foraging effort has been obtained previously using tracks of breeding macaroni penguins, suggesting that a common population level strategy operates (Trathan et al. 2006). This fact that penguins concentrate their foraging effort in certain areas was well predicted by our study, probably as a result of the broad base of habitat use gathered from the interbreeding period tracks. The basis of the habitat model for gentoo penguins was derived from tracking juveniles. Here again, the patterns obtained at the colony level revealed reasonably coherent dispersal patterns associated with the topographic environment, even though the tracking duration was relatively short.

Outside the breeding period, we studied (supposedly) experienced adult macaroni penguins, while for gentoo penguins, we based our knowledge on non-experienced, 'naive' animals. We acknowledge that juveniles may not be as good predictors of the behaviour of breeding animals as may be non-breeding adults, as recently-fledged juveniles have to learn how to efficiently exploit their environment. However, the tracking of juvenile gentoo penguins amounted to more than 53 days on average, a duration previously seen as long enough to reflect habitat choices made by penguins free from breeding constraints (e.g. Rey et al. 2007). We can also see this duration as long enough to assume that the juveniles did not die by inability to exploit their environment and find food, since apparently, these data allowed us to reasonably predict suitable habitat areas for breeding adults. Moreover, since four of the six tracked birds stopped transmitting on the same day, and one of them started transmitting again several months later from a close marine location, we believe that tracking ended because of technical issues of unknown origin, and not due to any mortality of animals associated with their failure to find suitable habitat.
It is generally recognized that interannual variability in environmental conditions might impact the at-sea distribution of animals. However, according to Trathan et al. (2006), penguins show very consistent interannual at-sea distribution during the breeding season. Outside the breeding period, there are also a number of studies on seabirds that suggest site philopatry (Phillips et al. 2005, Rey et al. 2007), adding strength to our conclusions and suggesting that, though few in number in most cases, our samples are representative.

\section{Conclusions and perspectives}

Our study confirms that the breeding period is associated with a reduction in the available habitat for central place foraging animals such as seabirds, and importantly, suggests that mechanisms and criteria for habitat selection are the same during and outside the breeding periods, given the available environment. Environmental variability, including seasonal effects of prey, potentially drives the larger scale movements observed outside the breeding period. These conclusions are relevant for the two species studied in this work, although these were two contrasting species. Further, this study highlighted that the respective optimal habitats of these species are clearly segregated, between the pelagic macaroni penguins (Fig. 4), the shelf-associated gentoo penguins from the open sea (Fig. 5) and the coastal gentoo penguins from the Golfe du Morbihan (Fig. 6). These major diving predators therefore seem to utilize a large range of the depths available in the marine environment surrounding Iles Kerguelen, and such habitat partitioning along other ecological dimensions (such as diet) may elucidate how four sympatric penguin species coexist on Iles Kerguelen (Weimerskirch et al. 1988).

Though beyond our practical abilities, it would have been interesting to have collected information about the actual foraging locations of the animals tracked, in order to exclude the travelling/exploring parts of their trips, and therefore allowing us to draw stronger conclusions about the favourable habitats experienced. The time of the year, as well as the size and proximity of the locations of colonies of conspecifics may also have been valuable proxies for prey availability that could have been included into the models, so that habitat suitability levels would better reflect the at-sea ecology of these predators. Comparing the results we obtained for the non-breeding period with the tracking of non-breeding adults during the breeding season would also have been a useful control to help clarify which factor (season or breeding status) was responsible for the long range migration patterns observed.

Our study highlights the pelagic specialization of macaroni penguins, possibly explaining why the colonies of this species are exclusively situated at the extreme ends of the Iles Kerguelen (Weimerskirch et al. 1988). However, female macaroni penguins make daily trips to sea to feed 
their chicks before the chicks are thermally independent (Stahl et al. 1985). Given this short time available at sea, they would not be able to reach pelagic areas. Therefore, it would be interesting to know to what extent they modify their habitat requirements during the breeding phase when time is in short supply.

For gentoo penguins, our results on juveniles showed that naive animals from different environments (closed vs open sea) target different habitats. Therefore, we assume that genetic isolation between the penguins from both environments may take place in their separate breeding grounds, possibly linked to their separate foraging grounds. Feasibly this may be driven by the different prey targeted (Lescroël et al. 2004).

In both species studied, the recent population declines measured worldwide may be linked to food availability (Lescroël \& Bost 2006, Cresswell et al. 2008). Consequently, knowledge about the habitats used by these species is essential if we are to understand what drives population processes, particularly in an era of rapid environmental change. Our study highlights that simply focusing on the breeding period is almost certainly insufficient to fully understand the ecological requirements of these species and their vulnerability to changes in marine resources.

\section{Acknowledgements}

The Ethics Committee of Institut Polaire Français PaulÉmile Victor approved all field procedures. The authors thank Y. Charbonnier, S. Mortreux, R. Perdriat, J. Nezan, V. Chartendraux, E. Pettex, C. Marteau, J.-L. Chill and F. Le Bouard for their help in the field, and A. Goarant, A. Villers, C. Péron, and A. Pinot for their help and advice with analyses. The present work was supported financially and logistically by the ANR 07 Biodiv 'GLIDES', the Zone Atelier Antarctique (INSU-CNRS), the Institut Polaire Français Paul-Emile Victor (IPEV, programmes no. 394 and 109) and the Terres Australes et Antarctiques Françaises administration. We also thank the reviewers for their very helpful and constructive comments.

\section{References}

Ainley, D.G., Ribic, C.A., Ballard, G., Heath, S., Gaffney, I., Karl, B.J., Barton, K.J., Wilson, P.R. \& WebB, S. 2004. Geographic structure of Adélie penguin populations: overlap in colony-specific foraging areas. Ecological Monographs, 74, 159-178.

Ashmole, N.P. 1963. The regulation of numbers of tropical oceanic birds. Ibis, 103, 458-473.

Birt, V.L., Birt, T.P., Goulet, D., Cairns, D.K. \& Montevecchi, W.A. 1987. Ashmole's halo: direct evidence for prey depletion by a seabird. Marine Ecology Progress Series, 40, 205-208.

Bost, C.A. \& Jouventin, P. 1990. Evolutionary ecology of the gentoo penguin (Pygoscelis papua). In DARBY, J.T. \& DAVIS, L.S., eds. Penguin biology. Orlando, FL: Academic Press, 85-112.
Bost, C.A., Thiebot, J.B., Pinaud, D., Cherel, Y. \& Trathan, P.N. 2009. Where do penguins go during the interbreeding period? Using geolocation to track the winter dispersion of the macaroni penguin. Biology Letters, 5, 473-476.

BRooke, M.D. 2004. The food consumption of the world's seabirds. Proceedings of the Royal Society of London, B271, S246-S248.

BRown, C.R. 1987. Travelling speed and foraging range of macaroni and rockhopper penguins at Marion Island. Journal of Field Ornithology, 58, 118-125.

Calenge, C., Darmon, G., Basille, M., Loison, A. \& Julien, J.-M. 2008. The factorial decomposition of the Mahalanobis distances in habitat selection studies. Ecology, 89, 555-566.

Charrassin, J.B., Park, Y.H., Le Maho, Y. \& Bost, C.A. 2002. Penguins as oceanographers unravel hidden mechanisms of marine productivity. Ecology Letters, 5, 317-319.

Clarke, A. 1988. Seasonality in the Antarctic marine environment. Comparative Biochemistry and Physiology, B90, 461-473.

Cresswell, K.A., Wiedenmann, J. \& Mangel, M. 2008. Can macaroni penguins keep up with climate- and fishing-induced changes in krill? Polar Biology, 31, 641-649.

Croxall, J.P. \& Prince, E.D. 1980. Food, feeding ecology and ecological segregation of seabirds at South Georgia. Biological Journal of the Linnean Society, 14, 103-131.

Croxall, J.P., Silk, J.R.D., Phillips, R.A., Afanasyev, V. \& Briggs, D.R. 2005. Global circumnavigations: tracking year-round ranges of nonbreeding albatrosses. Science, 307, 249-250.

Deagle, B.E., Gales, N.J. \& Hindell, M.A. 2008. Variability in foraging behaviour of chick-rearing macaroni penguins Eudyptes chrysolophus and its relation to diet. Marine Ecology Progress Series, 359, 295-309.

Durant, J.M., Huermann, D.Ø., Anker-Nilssen, T., Beaugrand, G., Mysterud, A., Pettorelli, N. \& Stenseth, N.C. 2005. Timing and abundance as key mechanisms affecting trophic interactions in variable environments. Ecology Letters, 8, 952-958.

Grémillet, D., Wilson, R.P., Wanless, S. \& Chater, T. 2000. Blackbrowed albatrosses, international fisheries and the Patagonian Shelf. Marine Ecology Progress Series, 195, 269-280.

Guisan, A. \& Zimmermann, N.E. 2000. Predictive habitat distribution models in ecology. Ecological Modelling, 135, 147-186.

Koslov, A.N., Shust, K.V. \& Zemsky, A.V. 1991. Seasonal and interannual variability in the distribution of Electrona carlsbergi in the southern Polar Front area. SC-CAMLR-SSP/7. Hobart: CCAMLR, 320-337.

LescroëL, A. \& Bost, C.A. 2005. Foraging under contrasting oceanographic conditions: the gentoo penguin at Kerguelen Archipelago. Marine Ecology Progress Series, 302, 245-261.

LescroëL, A. \& Bost, C.A. 2006. Recent decrease in gentoo penguin populations at Iles Kerguelen. Antarctic Science, 18, 171-174.

Lescrö̈L, A., Ridoux, V. \& Bost, C.A. 2004. Spatial and temporal variation in the diet of the gentoo penguin (Pygoscelis papua) at Kerguelen Islands. Polar Biology, 27, 206-216.

McConnell, B.J., Fedak, M.A., Burton, H.R., Englehard, G.H. \& ReIJNDERS, P. 2002. Movements and foraging areas of naive, recently weaned southern elephant seal pups. Journal of Animal Ecology, 71, $65-78$.

Mori, Y. \& Boyd, I.L. 2004. Segregation of foraging between two sympatric penguin species: does rate maximisation make the difference? Marine Ecology Progress Series, 275, 241-249.

Phillips, R.A., Silk, J.R.D., Croxall, J.P. \& Afanasyev, V. 2006. Yearround distribution of white-chinned petrels from South Georgia: relationships with oceanography and fisheries. Biological Conservation, 129, 336-347.

Phillips, R.A., Silk, J.R.D., Croxall, J.P., Afanasyev, V. \& Bennett, V.J. 2005. Summer distribution and migration of non-breeding albatrosses: individual consistencies and implications for conservation. Ecology, 86, 2386-2396. 
R Development Core Team 2009. R: a language and environment for statistical computing. Vienna: Wirtschafts Universität, http:// www.R-project.org.

Rey, A.R., Trathan, P.N., Pütz, K. \& Schiavini, A. 2007. Effect of oceanographic conditions on the winter movements of rockhopper penguins Eudyptes chrysocome chrysocome from Staten Island, Argentina. Marine Ecology Progress Series, 330, 285-295.

Robinson, S.A. \& Hindell, M.A. 1996. Foraging ecology of gentoo penguins Pygoscelis papua at Macquarie Island during the period of chick care. Ibis, 138, 722-731.

Stahl, J.C., Derenne, P., Jouventin, P., Mougin, J.L., Teulières, L. \& WeImerskiRch, H. 1985. Le cycle reproducteur des gorfous de l'archipel Crozet: Eudyptes chrysolophus, le Gorfou macaroni et Eudyptes chrysocome, le Gorfou sauteur. L'Oiseau et la Revue Française d'Ornithologie, 55, 27-43.

Tanton, J.L., Reid, K., Croxall, J.P. \& Trathan, P.N. 2004. Winter distribution and behaviour of gentoo penguins Pygoscelis papua at South Georgia. Polar Biology, 27, 299-303.

Trathan, P.N., Green, C., Tanton, J., Peat, H., Poncet, J. \& Morton, A. 2006. Foraging dynamics of macaroni penguins Eudyptes chrysolophus at South Georgia during brood-guard. Marine Ecology Progress Series, 323, 239-251.
Tsoar, A., Allouche, O., Steinitz, O., Rotem, D. \& Kadmon, R. 2007. A comparative evaluation of presence-only methods for modelling species distribution. Diversity and Distributions, 13, 397-405.

WeIMERSKIRCH, H. 2007. Are seabirds foraging for unpredictable resources? Deep-Sea Research II, 54, 211-223.

Weimerskirch, H., Zotier, R. \& Jouventin, P. 1988. The avifauna of the Iles Kerguelen. Еmu, 89, 15-29.

Weimerskirch, H., Pinaud, D., Pawlowski, F. \& Bost, C.A. 2007. Does prey capture induce area-restricted search? A fine-scale study using GPS in a marine predator, the wandering albatross. American Naturalist, 170, 734-743.

Williams, A.D. 1995. The penguins. Oxford: Oxford University Press, 295 pp. Wilson, R.P., Alvarrez, B., Latorre, L., Adelung, D., Culik, B. \& Bannasch, R. 1998. The movements of gentoo penguins Pygoscelis papua from Ardley Island, Antarctica. Polar Biology, 19, 407-413.

Wilson, R.P., Grémillet, D., Syder, J., Kierspel, M.A.M., Garthe, S., Weimerskirch, H., Schafer-Neth, C., Scolaro, J.A., Bost, C.A., Plötz, J. \& NeL, D. 2002. Remote-sensing systems and seabirds: their use, abuse and potential for measuring marine environmental variables. Marine Ecology Progress Series, 228, 241-261.

WoEHLER, E.J. 1993. The distribution and abundance of Antarctic and subAntarctic penguins. Cambridge: Scientific Committee on Antarctic Research, $76 \mathrm{pp}$. 